\title{
Assessment of Self-Esteem and its Correlation with Happiness in Adolescents
}

\author{
Bharat Reddy', Shailaja Mane $e^{2}$, Sharad R Agarkhedkar
}

${ }^{1}$ Resident, ${ }^{2}$ Professor, ${ }^{3}$ Professor and Head of Department of Paediatrics, Dr. D.Y. Patil Medical College, Hospital and Research Centre, Dr. D.Y. Patil Vidyapeeth, Pune, Maharashtra, India.

DOI: https://doi.org/10.24321/2349.2880.201907

\section{I $\quad \mathbf{N} \quad \mathbf{F} \quad \mathbf{O}$}

\section{Corresponding Author:}

Bharat Reddy, Department of Paediatrics, Dr. D.Y. Patil Medical College, Hospital and Research Centre, Dr. D.Y. Patil Vidyapeeth, Pune , Maharashtra, India.

E-mail Id:

bharatreddyganta@gmail.com

Orcid Id:

https://orcid.org/0000-0001-6918-8257

How to cite this article:

Reddy B, Mane S, Agarkhedkar S. Assessment of Self-Esteem and its Correlation with Happiness in Adolescents. Ind J Youth Adol Health 2019; 6(2): 3-6.

Date of Submission: 2019-12-15

Date of Acceptance: 2019-01-08

\section{$\begin{array}{llllllll}\mathbf{A} & \mathbf{B} & \mathbf{S} & \mathbf{T} & \mathbf{R} & \mathbf{A} & \mathbf{C} & \mathbf{T}\end{array}$}

Background: Adolescence is critical process allowing individual to leave childhood and enter into autonomous adulthood. Self-esteem has a strong relation to happiness, health and well-being. Although the research has not clearly established causation, we are persuaded that high self-esteem does lead to greater happiness. Low self-esteem is more likely to lead to depression. Most of the research till date was conducted in adult population, very few studies are on adolescents.

Objective: Assessment of self-esteem and correlate with psychological well-being in adolescents.

Methods: 400 school going adolescents were enrolled and questionnaire regarding self-esteem and happiness score were given, later assessed and correlated.

Result: Majority of students (84\%) were having moderate self-esteem score; $53.75 \%$ had normal happiness score. Mean self-esteem score was increasing with age, girls were having more self-esteem score than boys. Significant positive correlation was observed between self-esteem score and happiness score.

Conclusion: Adolescents with high self-esteem are happier than adolescent with low self-esteem. Improvement in self-esteem will be useful to reduce mental health issues in teenagers.

Keywords: Adolescent, School Health, Self-Esteem, Happiness

\section{Introduction}

WHO has defined adolescence as the age between 1019 years. ${ }^{1}$ Knock defined adolescence as the span of the young person's life between the obvious onset of puberty and completion of bone growth? There are 253.2 million adolescents - nearly one-fifth (20.9 per cent) of India's total population as per Census 2011. ${ }^{2}$ Adolescence is a crucial time when major physical, psychological and behavioural changes take place. The biological changes of puberty and brain remodeling occur intensively during these years.
An adolescent's capability to make decisions depends on his/her emotions, impulses, aggression and instinctive behaviour and this has an important effect on the selfesteem. ${ }^{3}$ Self-esteem is centered around introspection - the judgment made about one's overall growth and this is dependent on many factors ${ }^{4}$ like childhood experiences, family lives, parenting styles, friends/ peer influences, relationships, body images, temperament, prolonged hospitalization and abuse. The Rosenberg self-esteem scale is used to objectively gauge self-esteem. Self-esteem 
and one's sense of well-being go hand in hand. Well-being is the state of being comfortable, happy and healthy. ${ }^{5}$ Happiness is a mental or emotional state of well-being defined by positive or pleasant emotions ranging from contentment to intense joy. Happy mental states may reflect on the judgment made by a person about his/ her overall well-being. The Subjective happiness score is used to quantify happiness. ${ }^{6}$

It has been noticed that high self-esteem has a positive implication on psychological well-being. Improving selfesteem improves well-being. This study helps us study the quantitative correlation between self-esteem and happiness.

\section{Material and Method}

After institutional ethics committee clearance, the proposed study was conducted for 2 years in department of paediatrics of tertiary care institute, Pune. It as a crosssectional study included 400 school going adolescents aged between $11-15 y r s\left(8^{\text {th }}, 9^{\text {th }}, 10^{\text {th }}\right.$ standard) in Pimpri Chinchwad Corporation area (PCMC). Those who agree to participate in the study by giving written assent and consent, apparently healthy students without any chronic illness were included. Age group above 16 yrs., below 11 yrs., Adolescents suffering from endocrine disorder, chronic diseases and cardiovascular, respiratory, musculoskeletal, renal diseases. Are not included in this study.

\section{Study Protocol}

A study proforma in English was used to collect data. Rosenberg self-esteem scale and subjective happiness scale questionnaires were also used. Each question of the scales was well explained to the students for better understanding.

\section{Result}

Table I.Age and gender wise distribution of cases in the study

\begin{tabular}{|c|c|c|}
\hline Age (Yrs.) & No of cases & Percentage \\
\hline 12 & 3 & .8 \\
\hline 13 & 120 & 30.0 \\
\hline 14 & 174 & 43.5 \\
\hline 15 & 98 & 24.5 \\
\hline 16 & 5 & 1.3 \\
\hline Total & 400 & 100.0 \\
\hline Sex & & \\
\hline Boys & 224 & 56 \\
\hline Girls & 176 & 44 \\
\hline Total & 400 & 100.0 \\
\hline
\end{tabular}

It was observed that majority of adolescents in the present study were of 14 years (43.5\%) age followed by 13 years $(30 \%)$ and 15 years of age $(24.5 \%)$. It was seen that $56 \%$ students were Boys and $44 \%$ were Girls.

Table 2.Distribution of Self-esteem and Happiness scores in the study adolescents

\begin{tabular}{|c|c|c|}
\hline Self-esteem score & No of cases & Percentage \\
\hline Low (0-14) & 37 & 9.25 \\
\hline Moderate (15-25) & 336 & 84 \\
\hline High (26-30) & 27 & 6.75 \\
\hline
\end{tabular}

\begin{tabular}{|c|c|c|}
\hline Happiness score & & \\
\hline$<4.5$ (Less happy) & 87 & 21.75 \\
\hline $4.5-5.5$ (Normal) & 215 & 53.75 \\
\hline $5.6-7$ (More happy) & 98 & 24.5 \\
\hline Total & 400 & 100 \\
\hline
\end{tabular}

In this study, $84 \%$ students were having moderate selfesteem score (15-25) while $9.25 \%$ were having low selfesteem (0-14) and 6.75\% had high self-esteem score (26-30).

It was observed that majority of the students (53.75\%) had normal happiness score (4.5-5.5) while $24.75 \%$ students were more happy having high happiness score (5.6-7). But $21.75 \%$ students were less happy having low happiness score $(<4.5)$.

Table 3.Comparison of self-esteem score according to age in the study

\begin{tabular}{|c|c|c|c|c|c|}
\hline \multirow{2}{*}{$\begin{array}{c}\text { Age } \\
\text { (Years) }\end{array}$} & \multirow[b]{2}{*}{$\mathbf{N}$} & \multicolumn{2}{|c|}{ Self-esteem score } & \multirow{2}{*}{ f-value } & \multirow{2}{*}{ p-value } \\
\hline & & Mean & SD & & \\
\hline 12 & 3 & 17.00 & 2.646 & \multirow{5}{*}{1.39} & \multirow{5}{*}{0.24} \\
\hline 13 & 120 & 19.43 & 3.854 & & \\
\hline 14 & 174 & 19.13 & 3.937 & & \\
\hline 15 & 98 & 20.08 & 3.177 & & \\
\hline 16 & 5 & 20.20 & 4.087 & & \\
\hline
\end{tabular}

It was observed that the mean self-esteem score was increasing with age but the difference observed was not statistically significant $(p=0.24)$.

Table 4.Comparison of self-esteem score according to sex in the study

\begin{tabular}{|c|c|c|c|c|c|}
\hline \multirow{2}{*}{ Sex } & & \multicolumn{2}{|c|}{ Self-esteem score } & \multirow{2}{*}{$\begin{array}{c}\text { MW test } \\
\text { z-value }\end{array}$} & p-value \\
\cline { 2 - 4 } & $\mathbf{N}$ & Mean & SD & 2-val & \\
\hline Boys & 224 & 19.09 & 3.484 & \multirow{2}{*}{2.14} & 0.032 \\
\hline Girls & 176 & 19.91 & 4.010 & & \\
\hline
\end{tabular}

It was observed that mean self-esteem score among Boys was $19.09 \pm 3.484$ while in girls it was $19.91 \pm 4.010$. The 
difference of self-esteem score between boys and girls was statistically significant $(p=0.032)$.

Significant positive correlation was observed between self-esteem score and happiness score with coefficient of correlation ( $r$-value) $0.453(p=0,001)$. Happiness score is increasing proportionately with Self-esteem score which is statistically significant $(P<0.0001)$.

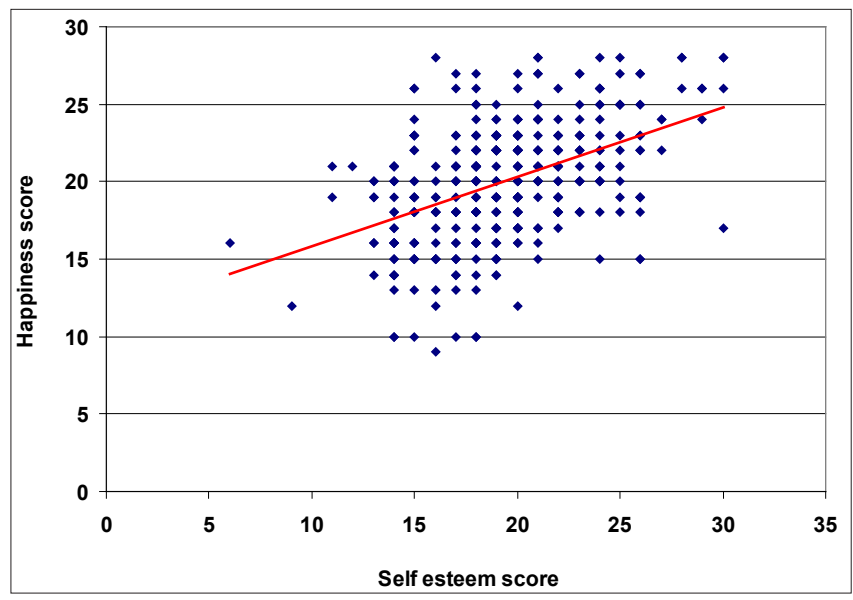

Figure I.Scatter diagram showing correlation between self-esteem score and happiness score in study group

\section{Discussion}

This study was conducted to assess and correlate selfesteem and happiness in 11-16 yrs. adolescents. Total 400 adolescent students of $8^{\text {th }}, 9^{\text {th }}$ and $10^{\text {th }}$ standard from private schools were included in this study. Self-esteem was assessed by using Rosenberg Self-Esteem Scale while well-being was assessed by using Subjective Happiness Scale. These scales are pre tested and validated worldwide.

It was observed that mean self-esteem score was increasing with the age but observed difference was not statistically significant $(F=1.39, p=0.24)$. Similar findings were also observed by Meera Padhy ${ }^{7}$ in their study.

It was observed that mean self-esteem score among boy students was $19.09 \pm 3.484$ while mean score of girls was $19.91 \pm 4.010$ and the difference observed was statistically significant $(p=0.032)$. Similar findings were also observed by Meera Padhy ${ }^{7}$ in their study.

Correlation between self-esteem score and happiness score showed positive correlation with coefficient of correlation as 0.453 indicating children with high self-esteem are happier and children with low self-esteem are less happy. Similar results were obtained by Meera Padhy ${ }^{7}$ stating significant correlation between self-esteem and subjective wellbeing and observed correlation coefficient of 0.61 . The results in this study are in line with the findings of Park and Jeong ${ }^{8}$ who also found that self-esteem was significantly and positively related with all the six subscales of psychological wellbeing. Paradise and Kernis ${ }^{9}$ and Freire and Tavares ${ }^{10}$ also found a significant and positive relationship between self-esteem and psychological wellbeing.

\section{Conclusion}

Majority of the adolescents (84\%) in the present study were having moderate self-esteem score. Most of the adolescents (53.75\%) have normal happiness score (4.4-5.5) indicating their psychological well-being. Self-esteem score was proportionately increasing with the age of adolescents. Adolescent girls are having better self-esteem than boys. The self-esteem was found to be significantly and positively related with happiness. This suggests that as self-esteem increases subjective happiness i.e., wellbeing.

Efforts should be made to improve self-esteem (e.g. life skills education) which will be useful to improve happiness index and in turn psychological well-being in adolescents. Improvement in self-esteem will be useful to reduce mental health issues in teenagers.

\section{Conflict of Interest: None}

\section{References}

1. WHO. Adolescence the critical phase, the challenges and the potential. published by W.H.O. Regional office for South-East Asia, New Delhi 1997. Available from: http://origin.searo.who.int/entity/child_adolescent/ topics/adolescent_health/adolescent_critical_phase/ en/.

2. Office of the Registrar General \& Census Commissioner, India. Available from: http://www.censusindia.gov.in.

3. The Australian parenting website. Available from: raisingchildren.net.au

4. Savin-Williams RC, Berndt TJ. Friendships and peer relations. SS Feldman and G R Elliott (Eds.). At the Threshold: The Developing Adolescent, 1990; 277-307). Cambridge, MA: Harvard University Press. Available from: https://psycnet.apa.org/record/1990-98975-010.

5. https://en.wikipedia.org/w/index.php?title=Wellbeing\&action=info/numQ7981051

6. Lyubomirsky S, Lepper $\mathrm{H}$. A measure of subjective happiness: Preliminary reliability and construct validation. Social Indicators Research 1999; 46(2): 137-155. Available from: https://escholarship.org/ content/qt2185n8gb/qt2185n8gb.pdf [Google Scholar].

7. Padhy M, Rana S, Mishra M. Self-esteem and Subjective Wellbeing: Correlates of Academic Achievement of Students. RJSSM 2011; 1(7): 149-156. Available from: https://pdfs.semanticscholar.org/43a9/d2a6d 59e1db390cfa8a219f1627a78760a55.pdf [Google Scholar].

8. Park H, Jeong DY. Psychological well-being, life satisfaction and self-esteem among adaptive 
perfectionists, maladaptive perfectionists and nonperfectionists. Personality and Individual Differences 2015; 72: 165-170. Available from: https://psycnet. apa.org/record/2014-48696-034 [Google Scholar].

9. Paradise AW, Kernis MH. Self-esteem and Psychological Well-being: Implications of Fragile Self-esteem. Journal of Social and Clinical Psychology 2002; 21: 345-361. Available from: https://psycnet.apa.org/ record/2002-15893-001 [Google Scholar].

10. Freire $T$, Tavares $D$. Influence of self-esteem and emotion regulation in subjective and psychological well-being of adolescents: Contributions to clinical psychology. Revista de Psiquiatria Clínica 2011; 38(5): 184-188. Available from: http://www.scielo.br/scielo.php?script=sci_ arttext\&pid=S0101-60832011000500003 [Google Scholar/ ResearchGate]. 